\title{
Inhibitory effect of ultrasonic stimulation on the voltage-dependent potassium currents in rat hippocampal CA1 neurons
}

Kun Cui ${ }^{1,2}$, Shuai Zhang ${ }^{1,2^{*}}$, Jinyao Sun ${ }^{1,2}$, Xueying Zhang ${ }^{1,2}$, Chong Ding ${ }^{1,2}$ and Guizhi Xu ${ }^{1,2}$

\begin{abstract}
Background: Transcranial ultrasonic stimulation is a novel noninvasive tool for neuromodulation, and has high spatial resolution and deep penetration. Although it can increase excitation of neurons, its effects on neuron are poorly understood. This study was to evaluate effect of ultrasonic stimulation (US) on neurons in vitro. In this paper, the effect of US on the excitability and voltage-dependent $K^{+}$currents of CA1 pyramidal neurons in the rat hippocampus was studied using patch clamp.

Results: Our results suggest that US increased the spontaneous firing rate and inhibited transient outward potassium current $\left(\boldsymbol{I}_{\boldsymbol{A}}\right)$ and delayed rectifier potassium current $\left(\boldsymbol{I}_{\boldsymbol{K}}\right)$. Furthermore, US altered the activation of $\boldsymbol{I}_{\boldsymbol{K}}$ channels, inactivation and recovery properties of $\boldsymbol{I}_{\boldsymbol{A}}$ channels. After $U S$, the $\boldsymbol{I}_{\boldsymbol{K}}$ activation curves significantly moved to the negative voltage direction and increased its slope factor. Moreover, the data showed that US moved the inactivation curve of $\boldsymbol{I}_{\boldsymbol{A}}$ to the negative voltage and increased the slope factor. Besides, US delayed the recovery of $\boldsymbol{I}_{\boldsymbol{A}}$ channel.
\end{abstract}

Conclusions: Our data indicate that US can increase excitation of neurons by inhibiting potassium currents. Different US decreased the voltage sensitivity of $\boldsymbol{I}_{\boldsymbol{K}}$ activation differentially. Moreover, the more time is needed for US to make the $\boldsymbol{I}_{\boldsymbol{A}}$ channels open again after inactivating. US may play a physiological role by inhibiting voltage-dependent potassium currents in neuromodulation. Our research can provide a theoretical basis for the future clinical application of ultrasound in neuromodulation.

Keywords: Ultrasonic stimulation, Delayed rectifier potassium current, CA1 pyramidal neuron, Transient outward potassium current, Patch clamp

\section{Background}

Therapeutic brain stimulation is a vital part of brain function research. Although they have been shown to be effective in treating neurological diseases, most of the current methods of stimulating the brain have some limitations. For instance, as a popular tool of brain stimulation, transcranial magnetic stimulation can modulate cognitive tasks while it is limited by poor spatial resolution [1-3]. Transcranial direct current stimulation also does not reach specific areas of the deep brain [4].

\footnotetext{
*Correspondence: zs@hebut.edu.cn

${ }^{1}$ State Key Laboratory of Reliability and Intelligence of Electrical

Equipment, Hebei University of Technology, No. 8 Hongrong Road,

Hongqiao District, Tianjin 300132, China

Full list of author information is available at the end of the article
}

Deep brain stimulation has precise targeting specificity whereas requires surgery and electrode implantation [5]. Focused ultrasound can stimulate specific areas of nerve tissue with a diameter of a few millimeters [6]. Transcranial ultrasound stimulation (TUS) requires no surgery and has high spatial resolution and deep penetration [710]. William J. Tyler et al. determined low intensity and low frequency ultrasound (LILFU) can exciting neurons and network activity remotely and noninvasively. Their results indicate that LILFU can activate voltage-dependent $\mathrm{Na}^{+}$channels and $\mathrm{Ca}^{2+}$ channels to induce neuronal activity [11]. Nicolas Wattiez et al. demonstrated that the neuromodulation effect of TUS on conscious behavioral monkeys can be assessed by real-time recording of discharge activity in brain regions connected to the 
stimulated region [12]. Using extracellular electrophysiology, Hongsun Guo and Mark Hamilton II et al. used TUS and performed brain mapping studies in guinea pigs. And they found an indirect auditory mechanism [13]. Whether it is the central nervous system or tumor, ultrasound provides a novel and effective strategy for targeted therapy [14-17].

Ultrasound stimulation (US) refers to TUS in vitro. US can produce the intramembrane mechano-electrical effect without tissue damage. US involves mechanoelectrical coupling. Such coupling is linked to changes of capacitance $[18,19]$. Inducing cavitation of lipid bilayer membranes, ultrasound can produce a mechano-electrical effect leading to neuronal excitation. It primarily is attributed to currents changes caused by the change of capacitance. The negative pressure of the ultrasonic waves pulled the leaflets apart each other whereas the positive pressure pushed forward. The average membrane capacitance is influenced by the dynamic deformed leaflets. Besides, ultrasound can affect mechanically sensitive ion channels to conduct currents [20]. The previous reported results verified that the activity of neurons can be excited by ultrasound through activation of some channel, which indicated great potential in the ultrasound therapy in ion channels [20-22].

Ion channels are excellent targets for diagnosis and therapy [23]. Whether as a major cause or as a mediator in the pathogenesis, they are involved in many diseases, such as epilepsy. In membranes of excitable and inexcitable cells, potassium channels are common and abundant $[24,25]$. By setting the membrane potential, potassium channels regulate the electrical excitability of the neurons, which is a major function of potassium channels. Furthermore, $\mathrm{K}^{+}$channel activity exerts an enormous function on signal pathways, among cell proliferation, differentiation and fusion [26, 27]. It is necessary to promote calcium entry that increased $K^{+}$channel activity and enhanced potassium efflux maintenance membrane hyperpolarization [28]. Besides, additional pathways for potassium channels such as to control the cell volume, are thought to involve in cell proliferation for which the membrane hyperpolarization is an essential requirement $[29,30]$. For shaping the action potential, voltagedependent potassium currents are important and can be divided into rapidly inactivating currents $\boldsymbol{I}_{\boldsymbol{A}}$ and noninactivating currents $\boldsymbol{I}_{\boldsymbol{K}}$ broadly [31, 32].

In our studies, we recorded the firing rates and the total current by whole-cell patch clamp apparatus and speculated that US affects potassium currents, which caused the increased spontaneous action potential frequency. Here, we investigated the impact of the US on potassium current, which is a major part of the outward current. During neuronal excitation, voltage-dependent potassium currents play a significant role in making the depolarized cell resting [33]. During the repolarizing phase, $\boldsymbol{I}_{\boldsymbol{A}}$ and $\boldsymbol{I}_{\boldsymbol{K}}$ are the main currents of the neuronal action potential [34]. In this study, we observed whether US has effects on $\boldsymbol{I}_{\boldsymbol{A}}$ and $\boldsymbol{I}_{K}$ of CA1 pyramidal neurons.

\section{Methods}

\section{Brain slices preparation}

1-2 weeks old juvenile Sprague-Dawley male rats, were purchased from Chinese People's Liberation Army Academy of Military Medical Laboratory Animal Center. Upon arrival, the rats were placed in a $23 \pm 1{ }^{\circ} \mathrm{C}$ chamber with a cycle of $12 \mathrm{~h}$ day and $12 \mathrm{~h}$ night. Veterinarians performed standard monitoring for a period of time prior to the experiment. Rats can get diet. The experimental animal studies were worked on the basis of institutional guidelines for animal experiments and the International Pain Research Association's ethical guidelines. Brain slice cultures were prepared from the rats. The intraperitoneal of rats were injected with pentobarbital $(130 \mathrm{mg} /$ $\mathrm{kg}$ ), and then the rats were anaesthetized. The anesthetized rats were decapitated, and the brains were removed. The brains were transferred into cold $\left(0{ }^{\circ} \mathrm{C}\right)$ slicing solution (in mmol: $2.40 \mathrm{KCl}, 6.00 \mathrm{MgCl}_{2}, 1.00 \mathrm{CaCl}_{2}, 24.50$ $\mathrm{NaHCO}_{3}, 1.25 \mathrm{NaH}_{2} \mathrm{PO}_{4}, 11.00$ glucose, 225.00 sucrose; adjusting $\mathrm{pH}$ 7.4, with $\mathrm{KOH}$ and $\mathrm{HCl}$ ) aerated with a mixture of gas with $95 \% \mathrm{O}_{2}$ and $5 \% \mathrm{CO}_{2}$ for $30 \mathrm{~s}$. In the ice cold slicing solution, the brain was rapidly cut into hemispheres, and $330 \mu \mathrm{m}$ thick horizontal slices was prepared by using a microtome (VT1200S, Leica, Nussloch, Germany). The brain tissue slices were cultured at a temperature of $37-39^{\circ} \mathrm{C}$ inside a holding chamber on an interface between oxygenated artificial cerebrospinal fluid (aCSF; in mmol: 11.00 glucose, $3.00 \mathrm{KCl}, 2.00 \mathrm{CaCl}_{2}, 2.00 \mathrm{MgCl}_{2}$, $123.00 \mathrm{NaCl}, 1.25 \mathrm{NaH}_{2} \mathrm{PO}_{4}, 24.50 \mathrm{NaHCO}_{3}$; adjusting $\mathrm{pH} 7.4$ with $\mathrm{KOH}$ and $\mathrm{HCl}$ ) and $95 \% \mathrm{O}_{2} / 5 \% \mathrm{CO}_{2}$ for at least $45 \mathrm{~min}$.

\section{Stimulation protocol}

The brain slice culture chamber is composed of a holder with a cylinder in a beaker and an outer wall. The pulsed ultrasound signals were generated by a radio-frequency power amplifier (Model 150A 100C, AR, WA, USA), an ultrasonic transducer (V308, Olympus, Tokyo, Japan) and an arbitrary waveform generator (33500B, KEYSIGHT, CA, USA). Ultrasonic transducer immersed in aCSF and was $1.5 \mathrm{~cm}$ above brain slice. The ultrasonic beam produced by the transducer (diameter $=24 \mathrm{~mm}$ ) stimulates the entire brain slice (length $<9 \mathrm{~mm}$, width $<6 \mathrm{~mm}$ ). The ultrasound settings were $0.5 \mathrm{MHz}$ center frequency, $20 \mathrm{~Hz}$ pulse repetition frequency, 50\% duty cycle and $20 \mathrm{~ms}$ pulse length, and the pulse-average ultrasound intensities were $15 \mathrm{~mW} / \mathrm{cm}^{2}$ or $30 \mathrm{~mW} / \mathrm{cm}^{2}$. The current 
of brain slice without any stimulation and with ultrasonic stimulations were recorded as a control status (CTRL), $15 \mathrm{~mW} / \mathrm{cm}^{2}$ ultrasonic stimulation status $\left(15 \mathrm{~mW} / \mathrm{cm}^{2}\right.$ US) and $30 \mathrm{~mW} / \mathrm{cm}^{2}$ ultrasonic stimulation status (30 mW/ $\mathrm{cm}^{2} \mathrm{US}$, Fig. 1), respectively. The number of rats for each control and experimental group is $12(n=12)$. Four brain slices of each rat were used for control and experimental groups. All stimulations lasted $15 \mathrm{~min}$.

\section{Patch clamp electrophysiology}

Bathing in aCSF, the slices were visualized using infrared differential interference contrast microscopy (U-TV1X-2, Olympus, Tokyo, Japan). The voltages and currents of neuron cell membrane were collected by the amplifier of the patch clamp (EPC 10, HEKA, Pfalz, Germany). Borosilicate glass pipettes with resistances ranging from 4 to $9 \mathrm{M} \Omega$. The pipettes were shaped by using the laser micropipette puller (MODEL P97, Sutter Instruments, CA, USA). All experiments were at $24{ }^{\circ} \mathrm{C}$. The data was sampled at a frequency of $20 \mathrm{kHz}$, and was filtered at a frequency of $2 \mathrm{kHz}$ using Patchmaster software. For recording of spontaneous action potential, pipettes were filled with the solution (in mmol): $133.00 \mathrm{~K}$-gluconate, 2.00 $\mathrm{MgCl}_{2}, 2.00 \mathrm{MgATP}, 10.00 \mathrm{EGTA}, 10.00$ HEPES (keeping $\mathrm{pH} 7.4$ with $\mathrm{KOH}$ and $\mathrm{HCl}$ ). When the action potential was recorded, brain culture was in aCSF. For the recording of potassium currents, we filled

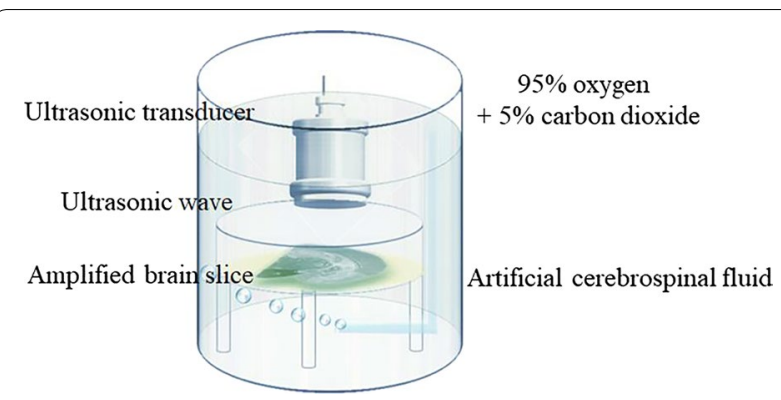

Fig. 1 Ultrasonic stimulation of brain slice the pipettes with the solution (in mmol): $2.00 \mathrm{CaCl}_{2}$, $121.00 \mathrm{KCl}, 10.00$ EGTA, $1.00 \mathrm{MgCl}_{2}, 10.00 \mathrm{HEPES}, 3.00$ $\mathrm{Na}_{2}$ ATP (keeping $\mathrm{pH} 7.4$, with $\mathrm{KOH}$ and $\mathrm{HCl}$ ). When the patch clamp experiments were performed, brain culture was bathed in a recording solution (in $\mathrm{mmol}$ ) 6.00 $\mathrm{KCl}, 1.00 \mathrm{MgCl}_{2}, 130.00 \mathrm{NaCl}, 2.00 \mathrm{CaCl}_{2}, 10.00$ Glucose, 10.00 HEPES (pH 7.4 with $\mathrm{KOH}$ and $\mathrm{HCl}$ ). When transient outward potassium current was indicated, it was pharmacologically isolated with (in mmol) 20.00 TEA$\mathrm{Cl}, 0.10 \mathrm{CdCl}_{2}$ and 0.001 Tetrodotoxin (TTX) injected to the bath solution to block the other channels. When delay rectifier potassium current was indicated, it was pharmacologically isolated with (in mmol) 4.00 AP, 0.10 $\mathrm{CdCl}_{2}$ and $0.001 \mathrm{TTX}$ injected to the bath solution. Three hippocampal CA1 neurons were recorded on each brain slice from 12 different rats respectively.

\section{Statistical analysis}

Statistical analysis was performed using Patchmaster (HEKA, Pfalz, Germany), Origin Pro 8.0 (OriginLab, Hampton, VA, USA), GraphPad Prism 7.0 (GraphPad Software, CA, USA) and SPSS 23 (IBM, NY, USA). The recording data were calculated as mean \pm SEM. We used one-way analysis of variance to statistically analyze the data. When $P<0.05$, the data were considered significant.

\section{Results}

The spontaneous action potentials were recorded without current injection for $6 \mathrm{~s}$ in the current-clamp mode (Fig. 2). Both the action potential frequency and amplitude in neurons were analyzed (Table 1). There were significant the increased firing frequency and amplitude of action potentials both in $15 \mathrm{~mW} / \mathrm{cm}^{2}$ US and $30 \mathrm{~mW} / \mathrm{cm}^{2} \mathrm{US}$. It indicated that the exposure to US increased excitability of the neurons.

For the recording of potassium currents, the membrane was maintained at a voltage of $-80 \mathrm{mV}$, and a $90 \mathrm{~ms}$ voltage pulse from -50 to $+100 \mathrm{mV}$ was applied in increase of $10 \mathrm{mV}$. When delay rectifier potassium currents were a

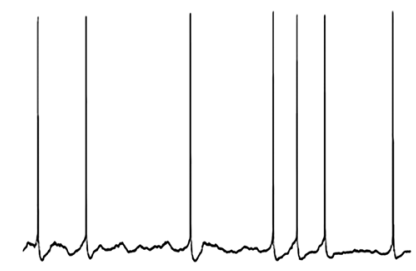

b

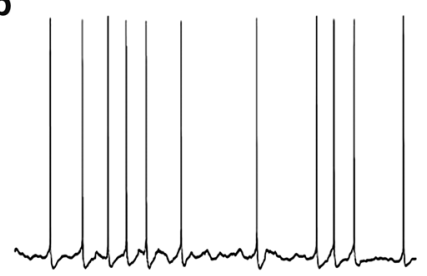

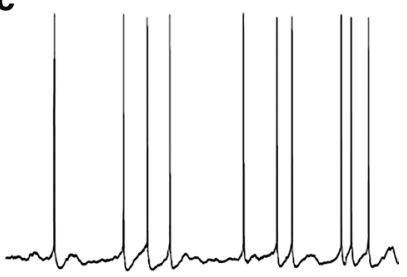

$25 \mathrm{mV}$

$1 \mathrm{~s}$

Fig. 2 Effects of US on spontaneous firing action potentials of neurons. a Control. b $15 \mathrm{~mW} / \mathrm{cm}^{2}$ US. c $30 \mathrm{~mW} / \mathrm{cm}^{2}$ US 
Table 1 Effects of stimulations on spontaneous action potentials of neurons

\begin{tabular}{lcl}
\hline Group & Frequency & Amplitude \\
\hline Control & $1.19 \pm 0.32$ & $101.91 \pm 4.19$ \\
$15 \mathrm{~mW} / \mathrm{cm}^{2}$ US & $1.80 \pm 0.29^{*}$ & $106.17 \pm 3.29^{*}$ \\
$30 \mathrm{~mW} / \mathrm{cm}^{2}$ US & $1.65 \pm 0.27^{*}$ & $105.33 \pm 3.72^{*}$ \\
\hline
\end{tabular}

$\mathrm{n}=12$, mean \pm SEM

${ }^{*} P<0.05$ versus control

indicated, the membrane was at a voltage of $-40 \mathrm{mV}$ and $300 \mathrm{~ms}$ voltage pulses were applied from -40 to $+50 \mathrm{mV}$ in incremental steps of $10 \mathrm{mV}$. The application of different US to brain slices produced obvious effects on the amplitudes of $\boldsymbol{I}_{\boldsymbol{A}}$ and $\boldsymbol{I}_{\boldsymbol{K}}$ in a different way (Figs. 3 and 4).
For neurons exposed to $15 \mathrm{~mW} / \mathrm{cm}^{2} \mathrm{US}$ and $30 \mathrm{~mW} / \mathrm{cm}^{2}$ US, the amplitudes of $\boldsymbol{I}_{\boldsymbol{A}}$ and $\boldsymbol{I}_{\boldsymbol{K}}$ were significantly lower than the Control neurons, which were indicated by current-voltage curves (Fig. 5). Therefore, we could determine that the potassium current values of US exposed neurons were significantly lower than other neurons.

The conductance was calculated by $\boldsymbol{G}=\boldsymbol{I}$ / $\left(V_{m}-V_{r e v}\right) . \quad I, V_{m}$ and $V_{r e v}$ denotes current density, the membrane voltage and the channel reversal potential. Figure $6 \mathrm{a}, \mathrm{b}$ showed activation curves of $\boldsymbol{I}_{\boldsymbol{A}}$ and $\boldsymbol{I}_{\boldsymbol{K}}$ after different stimulations respectively. We fitted the curves with a Boltzmann equation: $\boldsymbol{G} / \boldsymbol{G}_{\max }=\boldsymbol{I} /\left\{1+\exp \left[\left(V_{\boldsymbol{m}}-V_{\boldsymbol{h}}\right) / \boldsymbol{k}\right]\right\}$, in which $V_{\boldsymbol{h}}$ was the potential value in the semi-active state, $k$ was the slope factor. The effect of stimulation on $\boldsymbol{I}_{\boldsymbol{A}}$ and $\boldsymbol{I}_{\boldsymbol{K}}$
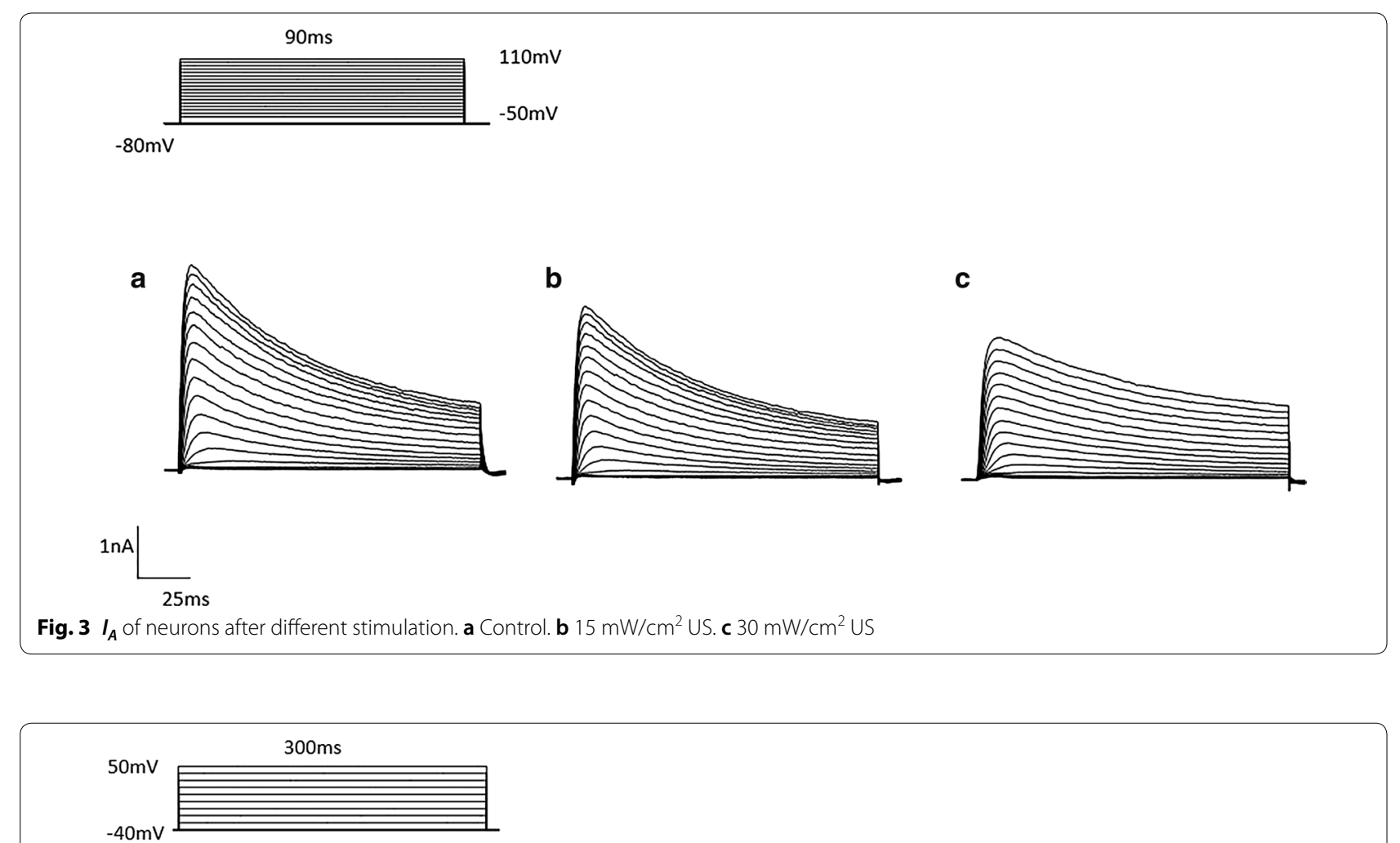

a

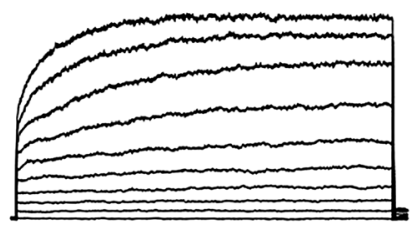

b

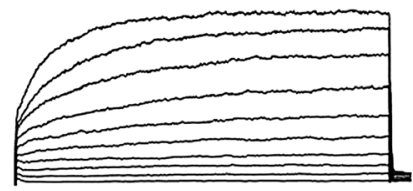

C

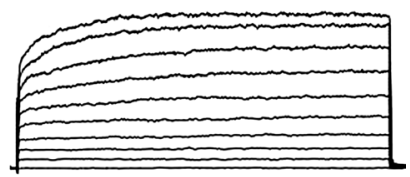

$1 \mathrm{nA}$

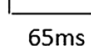

Fig. $4 I_{K}$ of neurons after different stimulation. a Control. b $15 \mathrm{~mW} / \mathrm{cm}^{2}$ US. c $30 \mathrm{~mW} / \mathrm{cm}^{2}$ US 

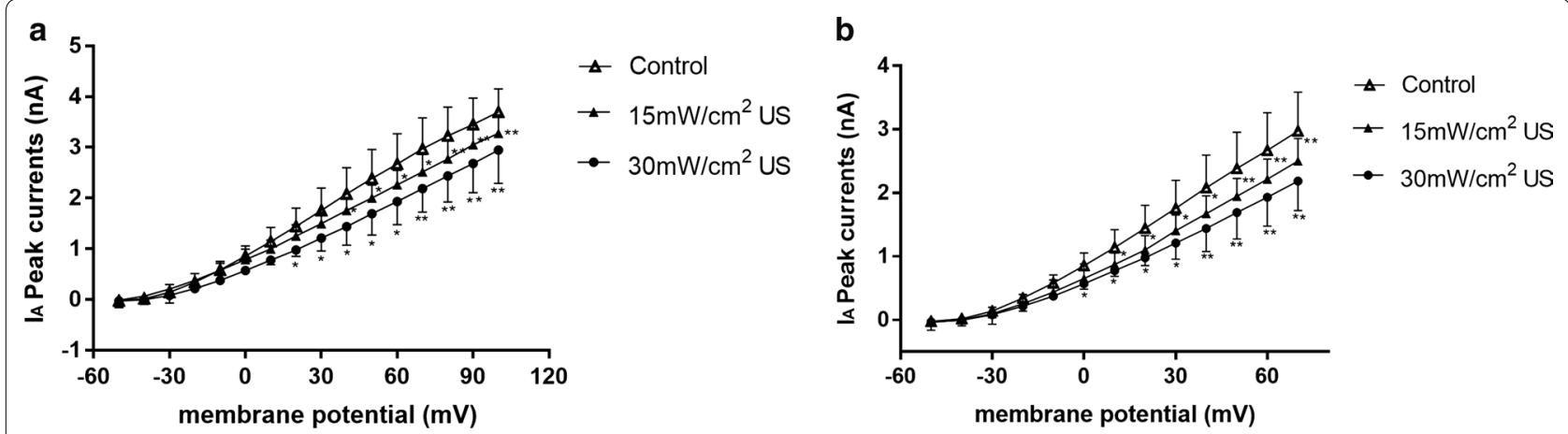

Fig. 5 The current-voltage relationship of $\mathbf{a} \boldsymbol{I}_{\boldsymbol{A}}$ and $\mathbf{b} \boldsymbol{I}_{\boldsymbol{K}}$. Data are represented as mean $\pm \operatorname{SEM}\left(\mathrm{n}=12,{ }^{*} P<0.05 \mathrm{vs}\right.$. control, ${ }^{*} P<0.01 \mathrm{vs}$. control)
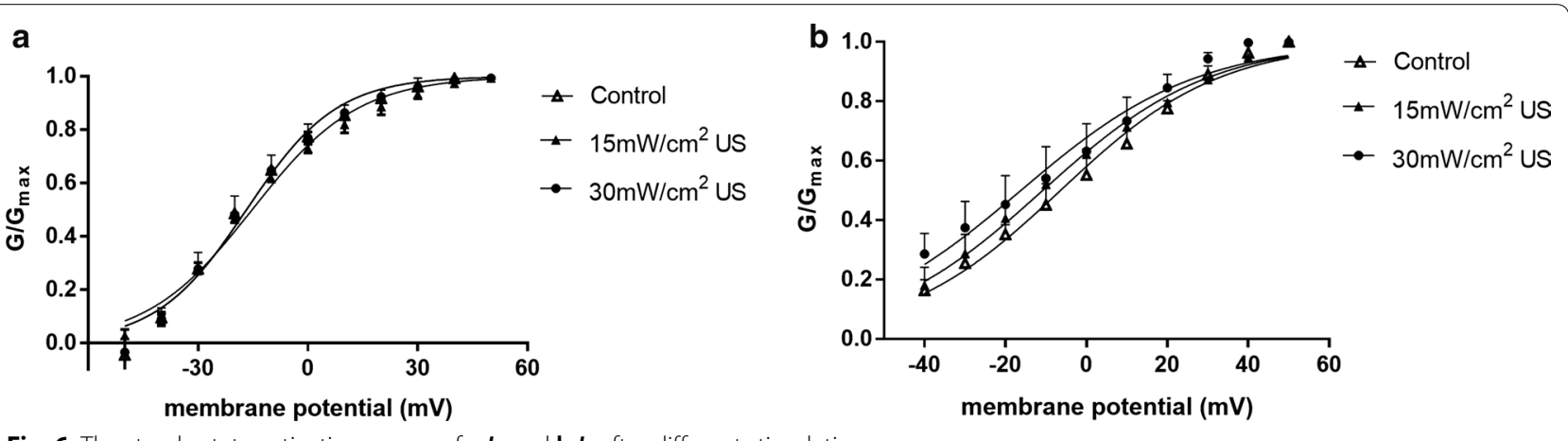

Fig. $\mathbf{6}$ The steady-state activation curves of $\mathbf{a} \boldsymbol{I}_{\boldsymbol{A}}$ and $\mathbf{b} \boldsymbol{I}_{\boldsymbol{K}}$ after different stimulation

Table 2 Effects of stimulations on the activation parameters of $I_{A}$ and $I_{K}$

\begin{tabular}{llllll}
\hline Groups & $\boldsymbol{I}_{\boldsymbol{A}}$ & & \multicolumn{1}{l}{$\boldsymbol{I}_{\boldsymbol{K}}$} \\
\cline { 2 - 3 } \cline { 5 - 6 } & $\boldsymbol{V}_{\boldsymbol{h}}$ & $\mathbf{k}$ & & $\boldsymbol{V}_{\boldsymbol{h}}$ & $\mathbf{k}$ \\
\hline Control & $-16.76 \pm 2.32$ & $12.45 \pm 2.03$ & $-6.45 \pm 2.61$ & $19.87 \pm 2.49$ \\
$15 \mathrm{~mW} /$ & $-15.19 \pm 1.72$ & $14.54 \pm 1.57$ & $-10.83 \pm 1.83^{*}$ & $20.60 \pm 1.83$ \\
$\mathrm{Cm}^{2}$ & & & & \\
US & & & & \\
$30 \mathrm{~mW}^{2}$ & $-16.68 \pm 1.91$ & $12.40 \pm 1.68$ & $-16.38 \pm 4.09^{*}$ & $22.20 \pm 4.05^{*}$ \\
$\mathrm{Cm}^{2}$ & & & & \\
US & & & &
\end{tabular}

$\mathrm{n}=12$, mean $\pm \mathrm{SEM}$

${ }^{*} P<0.05$ versus control

activation parameters was summarized in Table 2. It indicated that $15 \mathrm{~mW} / \mathrm{cm}^{2}$ US and $30 \mathrm{~mW} / \mathrm{cm}^{2}$ US have no significant effect on the activation characteristics of $I_{A}$. Furthermore, $15 \mathrm{~mW} / \mathrm{cm}^{2}$ US and $30 \mathrm{~mW} / \mathrm{cm}^{2}$ US induced a negative movement in this curve and decrease the slope factor.

The inactivation characteristics of $\boldsymbol{I}_{\boldsymbol{A}}$ were recorded by the double-pulse protocols (Fig. 7). But the inactivation of $\boldsymbol{I}_{\boldsymbol{K}}$ was not recorded because it is a type of long-lasting channels. The membrane was maintained at $-80 \mathrm{mV}$, changed to varying $90 \mathrm{~ms}$ prepulse voltages from -100 to $10 \mathrm{mV}$ in increase of $10 \mathrm{mV}$ and to an $80 \mathrm{~ms}$ test pulse at $+50 \mathrm{mV}$. After the peak amplitude of $\boldsymbol{I}_{\boldsymbol{A}}$ was normalized, it was drawn with above prepulse potential. We fitted the inactivation curves of $I_{A}$ with Boltzmann equation $I / I_{\max }=I /\left\{1+\exp \left[\left(V_{h}-V_{m}\right) / k\right]\right\}$, there $I / I_{\max }$ was a normalized current of $\boldsymbol{I}_{\boldsymbol{A}}, \boldsymbol{V}_{\boldsymbol{h}}$ was the semi-inactivation voltage value, $\mathrm{k}$ was the curve's slope factor (Fig. 9a). Both $15 \mathrm{~mW} / \mathrm{cm}^{2}$ and $30 \mathrm{~mW} / \mathrm{cm}^{2}$ US could significantly shift inactivation curve of $\boldsymbol{I}_{\boldsymbol{A}}$ to negative voltage direction and enhance its slope factor (Table 3).

In order to comprehend the recovery properties from inactivation, the membrane was maintained at $-80 \mathrm{mV}$ and stepped up to $+50 \mathrm{mV}$ for $90 \mathrm{~ms}$ (depolarizing pulse), then repolarized to $-80 \mathrm{mV}$ varying from 15 to $125 \mathrm{~ms}$ in $10 \mathrm{~ms}$ increments before a test pulse of $+50 \mathrm{mV}$ for $90 \mathrm{~ms}$ (Fig. 8). The amplitude of $\boldsymbol{I}_{\boldsymbol{A}}$, caused by above conditioning pulse, was defined as $\boldsymbol{I}_{1}$, and $\boldsymbol{I}_{2}$ was the peak current amplitude of the $\boldsymbol{I}_{\boldsymbol{A}}$ induced by test pulse. The characteristics of recovery after the inactivation can be analyzed using the value of $\boldsymbol{I}_{2} / \boldsymbol{I}_{1}$. We fitted the $I_{2} / I_{1}$ time curve with a mono-exponential equation: 


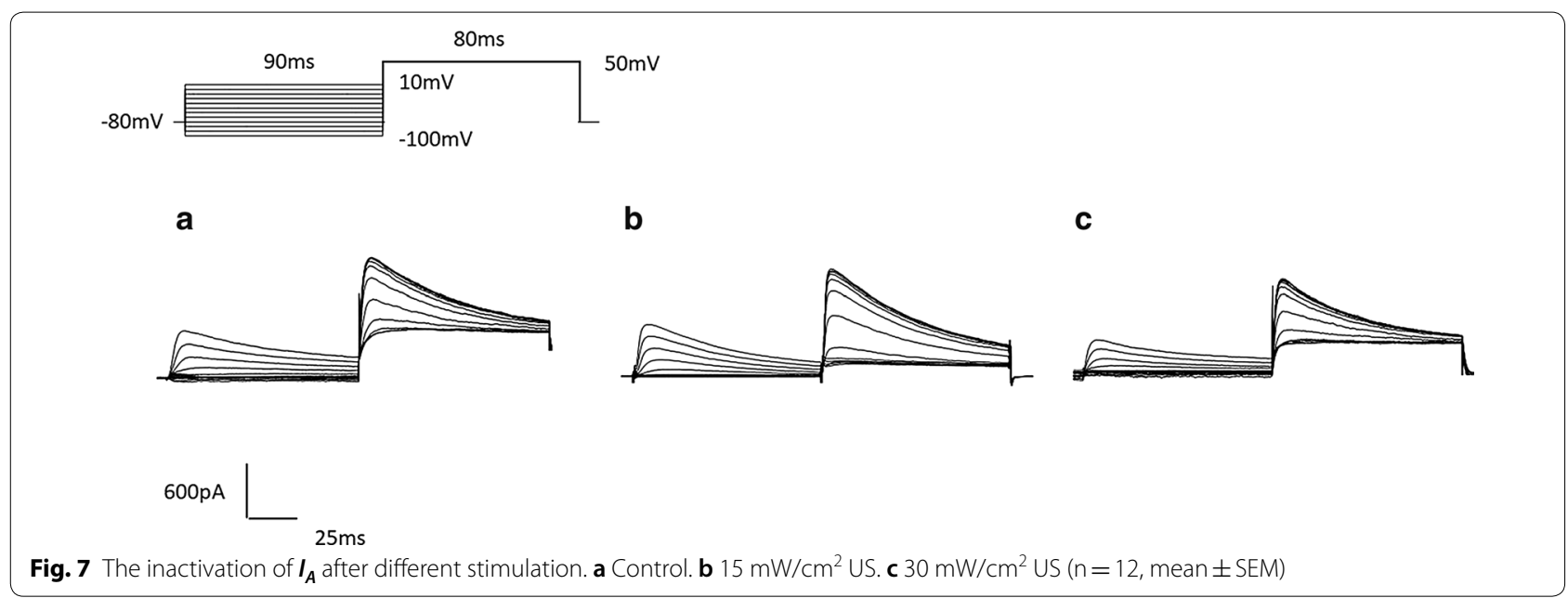

Table 3 Effects of stimulations on the inactivation parameters of $I_{A}$

\begin{tabular}{lll}
\hline Groups & \multicolumn{1}{|}{$\boldsymbol{I}_{\boldsymbol{A}}$} & $\mathbf{k}$ \\
\cline { 2 - 3 } & $\boldsymbol{V}_{\boldsymbol{h}}$ & $7.72 \pm 0.78$ \\
\hline Control & $-39.26 \pm 0.85$ & $9.05 \pm 2.08^{*}$ \\
$15 \mathrm{~mW} / \mathrm{cm}^{2}$ US & $-45.33 \pm 2.32^{*}$ & $8.62 \pm 2.55^{*}$ \\
$30 \mathrm{~mW} / \mathrm{cm}^{2}$ US & $-44.31 \pm 2.86^{*}$ & \\
\hline
\end{tabular}

$\mathrm{n}=12$, mean \pm SEM

${ }^{*} P<0.05$ versus control

$$
I / I_{\max }=A+B \exp (-t / \tau) .
$$

$\boldsymbol{I}$ is $\boldsymbol{I}_{2} / \boldsymbol{I}_{1}$ and $\boldsymbol{I}_{\max }$ is the maximal value of $\boldsymbol{I}$ and, $\tau$ is the time constant (Fig. 9b). Table 4 showed the time constants $\tau$. The results indicated that $15 \mathrm{~mW} / \mathrm{cm}^{2}$ US and $30 \mathrm{~mW} / \mathrm{cm}^{2}$ US could markedly increase the time constant of the recovery. Besides, $15 \mathrm{~mW} / \mathrm{cm}^{2}$ US and
$30 \mathrm{~mW} / \mathrm{cm}^{2}$ US shifted the recovery from inactivation curve of $\boldsymbol{I}_{A}$ to negative potential.

\section{Discussion}

There are many evidences supporting the fact that US has neuronal effects [16, 22]. However, the lasting effects of US on neuronal excitability are not entirely clarified, especially the ion channel mechanism. Our study demonstrates that US can increase the frequency, amplitude the duration of spontaneous action potential to enhance excitation of neurons. As a result of US, the durations of single action potential were prolonged. Therefore it might be inferred that the increasing frequency would be responsible for the delay of repolarization which depends on $\boldsymbol{I}_{\boldsymbol{A}}$ and $\boldsymbol{I}_{\boldsymbol{K}}$.

Participating in early polarization, $\boldsymbol{I}_{\boldsymbol{A}}$ is crucial to the spike threshold. $\boldsymbol{I}_{\boldsymbol{K}}$ cause the repolarization. The width of spike also depends on $\boldsymbol{I}_{\boldsymbol{K}}[32,35]$. In addition, $\boldsymbol{I}_{\boldsymbol{K}}$ is critical for post-peak hyperpolarization and affects the peak frequency of neurons.

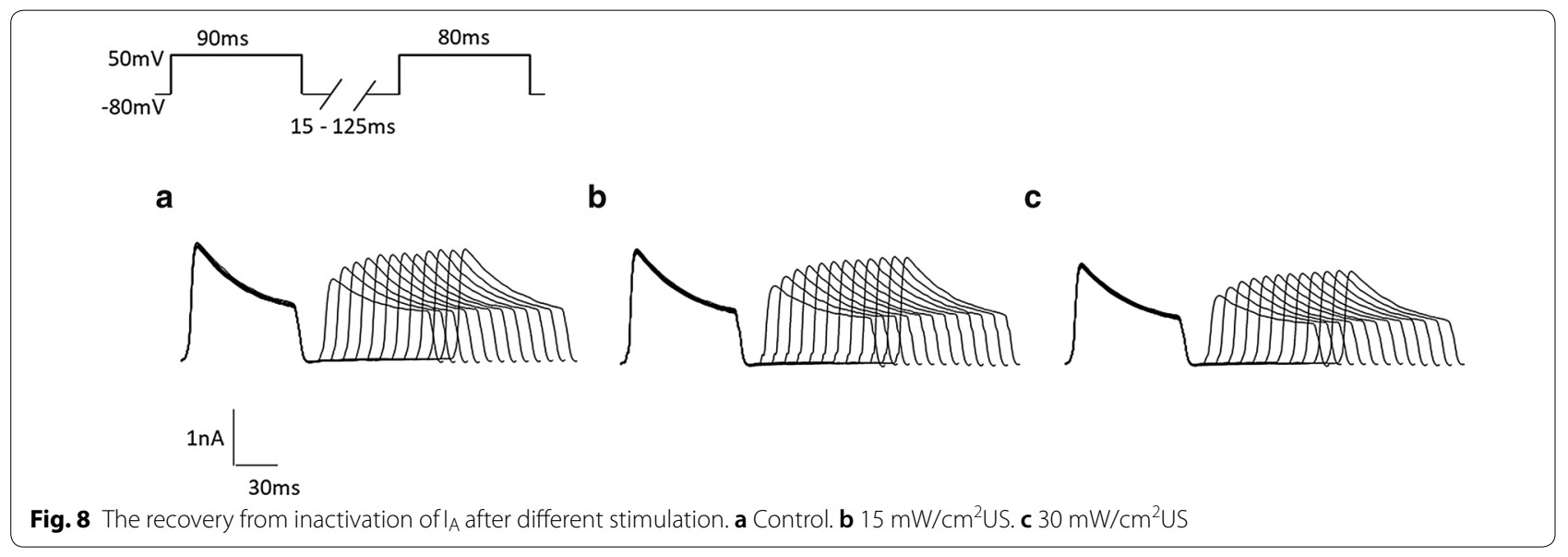



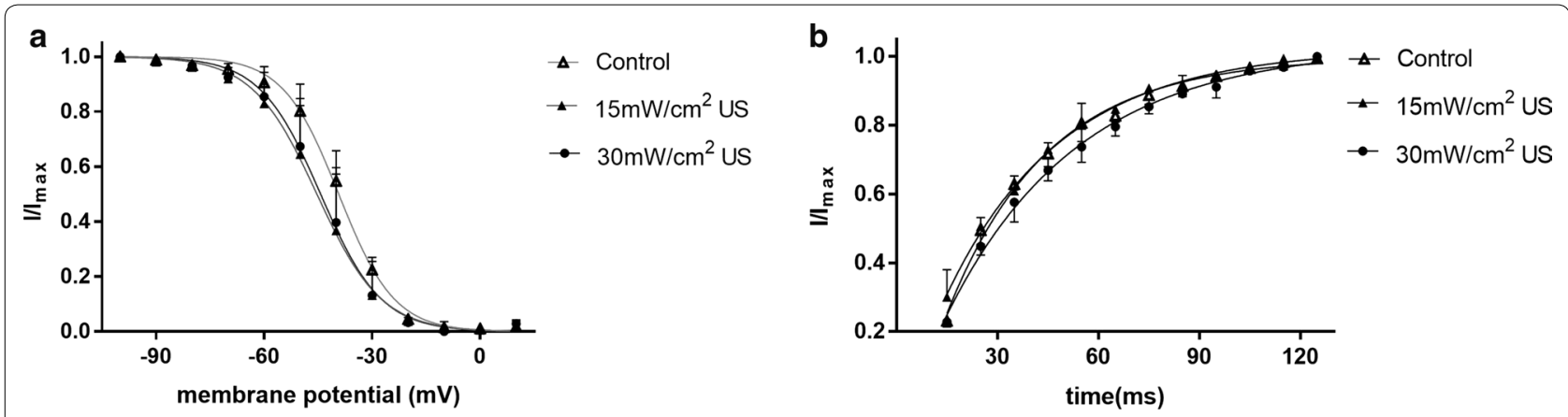

Fig. 9 a The inactivation curves of $I_{A}$. $\mathbf{b}$ recovery after inactivation curves of $I_{A}$

Table 4 Effects of stimulations on the recovery from inactivation parameters of $I_{A}$

\begin{tabular}{ll}
\hline Group & $\boldsymbol{\tau}$ \\
\hline Control & $30.58 \pm 4.59$ \\
$15 \mathrm{~mW} / \mathrm{cm}^{2}$ US & $35.46 \pm 6.09^{*}$ \\
$30 \mathrm{~mW} / \mathrm{cm}^{2}$ US & $40.25 \pm 6.39^{*}$
\end{tabular}

$\mathrm{n}=12$, mean \pm SEM

${ }^{*} P<0.05$ versus control

Therefore, to identify the ion channel mechanisms, we examined ion channels by analyzing the changes of $K^{+}$ currents characteristics by patch clamp recording. The results revealed that US enhanced excitability of neurons in CA1 pyramidal neurons of rat hippocampal, which may be mediated by a reduction of potassium currents. The US effectively inhibited $\boldsymbol{I}_{\boldsymbol{A}}$ and $\boldsymbol{I}_{\boldsymbol{K}}$, and this effects of $30 \mathrm{~mW} / \mathrm{cm}^{2}$ US were more than $15 \mathrm{~mW} / \mathrm{cm}^{2}$ US.

Furthermore, US significantly moved the activation curves of $\boldsymbol{I}_{\boldsymbol{K}}$ to the negative voltage. It is shown that different US affected the activation of $\boldsymbol{I}_{\boldsymbol{K}}$ differentially. Besides, US increased the slope factor for $\boldsymbol{I}_{\boldsymbol{K}}$ activation curve, indicating that the voltage sensitivity of activation reduced. Moreover, the data showed that US moved inactivation curve of $\boldsymbol{I}_{A}$ to the negative voltage and increased its slope factor. Besides, US delayed the recovery of $\boldsymbol{I}_{A}$. This means that the $\boldsymbol{I}_{\boldsymbol{A}}$ channel takes longer to open again after inactivation. These results suggest that US inhibited $\boldsymbol{I}_{\boldsymbol{A}}$ and $\boldsymbol{I}_{\boldsymbol{K}}$ via reducing the open number of $\boldsymbol{I}_{\boldsymbol{A}}$ and $\boldsymbol{I}_{\boldsymbol{K}}$ channels.

\section{Conclusions}

US can enhance neural excitation to activate the brain area, thereby altering the physiological processes in the brain. Potassium currents made the depolarized cell rest and are important during the action potential repolarizing. US can inhibit both $\boldsymbol{I}_{\boldsymbol{A}}$ and $\boldsymbol{I}_{\boldsymbol{K}}$ to increase excitation of neurons, particularly in high intensity of
US. In this sense, the fact that US enhance excitation of neuron and act differently on potassium currents could potentially be used to design neuromodulation tools for neurological diseases. Besides, ultrasound can provide a method for targeted ion channels therapy almost no side effects. In clinical use, ultrasound is a promising treatment for the diseases to improving excitability in certain brain area. For example, ultrasound may be achieve the purpose of treating neurological diseases such as treatment of dyskinesia, epilepsy, stroke sequelae by changing the local cortical excitability of the brain. This study provide a theoretical basis for clinical ultrasound application in neuromodulation.

\section{Abbreviations}

TUS: transcranial ultrasonic stimulation; US: ultrasonic stimulation; LILFU: lowintensity, low-frequency ultrasound; $\boldsymbol{I}_{A}$ : transient outward potassium current tetrodotoxin; TTX: tetrodotoxin; $\boldsymbol{I}_{\boldsymbol{K}}$ : delayed rectifier potassium currents; aCSF: artificial cerebrospinal fluid.

\section{Authors' contributions}

KC and SZ designed and studied. KC and JS conducted experiment and data processing. XZ, CD and GX co-performed experiments. KC, SZ, JS, XZ, CD and $G X$ reviewed the results, wrote this manuscript and gave final approval for publication.

\section{Author details}

1 State Key Laboratory of Reliability and Intelligence of Electrical Equipment, Hebei University of Technology, No. 8 Hongrong Road, Hongqiao District, Tianjin 300132, China. ${ }^{2}$ Key Laboratory of Electromagnetic Field and Electrical Apparatus Reliability of Hebei Province, Hebei University of Technology, Tianjin 300132, China.

\section{Acknowledgements}

The authors thank Mr. Zhenyu Zhou and Mr. Yaze Liu for the kind assistances in the experiment preparation.

\section{Competing interests}

The authors declare that they have no competing interests.

\section{Availability of data and materials}

During the current study, the datasets used and/or analyzed are available from the corresponding author upon reasonable request.

Consent for publication

Not applicable. 


\section{Ethics approval and consent to participate}

All experimental procedures were performed in accordance with the $\mathrm{CHN}$ Animal Protection Act and approved by the Hebei University of Technology Animal Care and Use Committee (Approval number: HEBUTaCUC2018006).

\section{Funding}

This study was funded in part by the National Natural Science Foundation of China under Grant Nos. 51677053, 51877069, 51737003 and the NFS of Hebei Province, China under Grant Nos. E2015202292, E2015202050 and E2017202190, Research Projects in Hebei Province, China under Grant Nos. C2015005012, ZD2017020 and BJ2016013.

\section{Publisher's Note}

Springer Nature remains neutral with regard to jurisdictional claims in published maps and institutional affiliations.

Received: 5 August 2018 Accepted: 26 December 2018

Published online: 05 January 2019

\section{References}

1. Kobayashi M, Pascual-Leone A. Transcranial magnetic stimulation in neurology. Lancet Neurol. 2003;2(3):145-56.

2. Kojima S, Onishi H, Sugawara K, et al. Modulation of the cortical silent period elicited by single-and paired-pulse transcranial magnetic stimulation. BMC Neurosci. 2013;14(1):43.

3. Tringali $S$, Perrot $X$, Collet $L$, et al. Repetitive transcranial magnetic stimulation: hearing safety considerations. Brain Stimul. 2012;5(3):354-63.

4. Fregni F, Pascualleone A. Technology insight: noninvasive brain stimulation in neurology-perspectives on the therapeutic potential of rTMS and tDCS. Nat Rev Neurol. 2007;3(7):383-93.

5. Ressler KJ, Mayberg HS. Targeting abnormal neural circuits in mood and anxiety disorders: from the laboratory to the clinic. Nat Neurosci. 2007;10(9):1116.

6. Kim H, Taghados SJ, Fischer K, et al. Non-invasive transcranial stimulation of rat abducens nerve by focused ultrasound. Ultrasound Med Biol. 2012:38(9):1568-75.

7. Tufail Y, Matyushov A, Baldwin N, et al. Transcranial pulsed ultrasound stimulates intact brain circuits. Neuron. 2010:66(5):681-94.

8. Bystritsky A, Korb AS. A review of low-intensity transcranial focused ultrasound for clinical applications. Curr Behav Neurosci Rep. 2015;2(2):60-6.

9. Naor O, Krupa S, Shoham S. Ultrasonic neuromodulation. J Neural Eng. 2016;13(3):031003.

10. Yuan Y, Yan J, Ma Z, et al. Noninvasive focused ultrasound stimulation can modulate phase-amplitude coupling between neuronal oscillations in the rat hippocampus. Front Neurosci. 2016;10:348.

11. Tyler WJ, Tufail Y, Finsterwald M, et al. Remote excitation of neuronal circuits using low-intensity. Low-frequency ultrasound. PLOS ONE. 2008;3(10):e3511.

12. Wattiez N, Constans C, Deffieux T, et al. Transcranial ultrasonic stimulation modulates single-neuron discharge in macaques performing an antisaccade task. Brain Stimul. 2017;10(6):1

13. Guo H, Mark Hamilton II, Offutt SJ, et al. Ultrasound produces extensive brain activation via a cochlear pathway. Neuron. 2018;98(5):1.

14. Ibsen S, Tong A, Schutt C, et al. Sonogenetics is a non-invasive approach to activating neurons in Caenorhabditis elegans. Nat Commun. 2015;6:8264.

15. Pan Y, Yoon S, Sun J, et al. Mechanogenetics for the remote and noninvasive control of cancer immunotherapy. Proc Natl Acad Sci USA. 2018;115(5):201714900
16. Elisabetta $S$, Natalia V. Acoustic neuromodulation from a basic science prospective. J Ther Ultrasound. 2016:4(1):17

17. Zhou W, Wang J, Wang K, et al. Ultrasound neuro-modulation chip: activation of sensory neurons in Caenorhabditis elegans by surface acoustic waves. Lab Chip. 2017:17(10):1725-31.

18. Plaksin M, Shoham S, Kimmel E. Intramembrane cavitation as a predictive bio-piezoelectric mechanism for ultrasonic brain stimulation. Phys Rev X. 2014;4(1):011004

19. Krasovitski B, Frenkel V Shoham S, et al. Intramembrane cavitation as a unifying mechanism for ultrasound-induced bioeffects. Proc Natl Acad Sci USA. 2011;108(8):3258-63.

20. Kubanek J, Shi J, Marsh J, et al. Ultrasound modulates ion channel currents. Sci Rep. 2016;6:24170

21. Ye J, Tang S, Meng L, et al. Ultrasonic control of neural activity through activation of the mechanosensitive channel MscL. Nano Lett. 2018;18:4148

22. Yan F, Li L, Deng Z, et al. Paclitaxel-liposome-microbubble complexes as ultrasound-triggered therapeutic drug delivery carriers. J Control Release. 2013;166(3):246-55

23. Catterall WA. Structure and function of voltage-sensitive ion channels. Science. 1988;242(4875):50-61.

24. Jan LY, Jan YN. Voltage-sensitive ion channels. Cell. 1989;56(1):13-25.

25. Yang JJ, Tian YT, Zhuo Y, et al. Effect of melamine on potassium currents in rat hippocampal CA1 neurons. Toxicol Vitro Int J Publ Assoc Bibra. 2010:24(2):397-403.

26. Catterall WA. Ion channel voltage sensors: structure, function, and pathophysiology. Neuron. 2010;67(6):915-28.

27. Jung S, Bang M, Kim BS, et al. Intracellular gold nanoparticles increase neuronal excitability and aggravate seizure activity in the mouse brain. PLoS ONE. 2014;9(3):e91360.

28. Santella L. The role of calcium in the cell cycle: facts and hypotheses. Biochem Biophys Res Commun. 1998;244(2):317-24.

29. Rouzaire-Dubois B, Dubois JM. $\mathrm{K}^{+}$channel block-induced mammalian neuroblastoma cell swelling: a possible mechanism to influence proliferation. J Physiol. 1998;510(1):93-102

30. Vaur S, Bresson-Bepoldin L, Dufy B, et al. Potassium channel inhibition reduces cell proliferation in the GH3 pituitary cell line. J Cell Physiol. 1998:177(3):402-10.

31. Stühmer W, Ruppersberg JP, Schröter KH, et al. Molecular basis of functional diversity of voltage-gated potassium channels in mammalian brain. EMBO J. 1989;8(11):3235-44.

32. Shan $D, X i e Y$, Ren $G$, et al. Inhibitory effect of tungsten carbide nanoparticles on voltage-gated potassium currents of hippocampal CA1 neurons. Toxicol Lett. 2012;209(2):129-35.

33. Oliver D, Lien CC, Soom M, et al. Functional conversion between A-type and delayed rectifier $\mathrm{K}^{+}$channels by membrane lipids. Science. 2004:304(5668):265-70.

34. Yu-Tao T, Zhao-Wei L, Yang Y, et al. Effect of alpha-cypermethrin and theta-cypermethrin on delayed rectifier potassium currents in rat hippocampal neurons. Neurotoxicology. 2009;30(2):269-73.

35. Pardo LA, Contreras-Jurado C, Zientkowska M, et al. Role of voltage-gated potassium channels in cancer. J Membr Biol. 2005;205(3):115-24.

Ready to submit your research? Choose BMC and benefit from

- fast, convenient online submission

- thorough peer review by experienced researchers in your field

- rapid publication on acceptance

- support for research data, including large and complex data types

- gold Open Access which fosters wider collaboration and increased citations

- maximum visibility for your research: over 100M website views per year

At $\mathrm{BMC}$, research is always in progress.

Learn more biomedcentral.com/submissions 